ARTICLE

\title{
Intermolecular [3+3] ring expansion of aziridines to dehydropiperi-dines through the intermediacy of aziridinium ylides
}

\author{
Josephine Eshon (1) 1,3, Kate A. Nicastri (1) 1,3, Steven C. Schmid ${ }^{1}$, William T. Raskopf1, Ilia A. Guzei (1) 1, \\ Israel Fernández (i) ${ }^{2} \&$ Jennifer M. Schomaker (i) ${ }^{1 凶}$
}

The importance of $\mathrm{N}$-heterocycles in drugs has stimulated diverse methods for their efficient syntheses. Methods that introduce significant stereochemical complexity are attractive for identifying new bioactive amine chemical space. Here, we report a $[3+3]$ ring expansion of bicyclic aziridines and rhodium-bound vinyl carbenes to form complex dehydropiperidines in a highly stereocontrolled rearrangement. Mechanistic studies and DFT computations indicate that the reaction proceeds through formation of a vinyl aziridinium ylide; this reactive intermediate undergoes a pseudo-[1,4]-sigmatropic rearrangement to directly furnish heterocyclic products with net retention at the new $\mathrm{C}-\mathrm{C}$ bond. In combination with asymmetric silver-catalyzed aziridination, enantioenriched scaffolds with up to three contiguous stereocenters are rapidly delivered. The mild reaction conditions, functional group tolerance, and high stereospecificity of this method are well-suited for appending piperidine motifs to natural product and complex molecules. Ultimately, our work establishes the value of underutilized aziridinium ylides as key intermediates for converting small, strained rings to larger $\mathrm{N}$-heterocycles.

\footnotetext{
${ }^{1}$ Department of Chemistry, University of Wisconsin, 1101 University Avenue, Madison, WI 53706, USA. ${ }^{2}$ Departamento de Química Orgánica I and Centro de Innovación en Química Avazanda (ORFEO-CINQA), Facultad de Ciencias Químicas, Universidad Complutense de Madrid, 28040 Madrid, Spain. ${ }^{3}$ These authors contributed equally: Josephine Eshon, Kate A. Nicastri. ${ }^{{ }^{*}}$ email: schomakerj@chem.wisc.edu
} 
T he importance of nitrogenated heterocycles in pharmaceuticals, natural products, and fine chemicals continues to drive innovative strategies for their efficient syntheses from readily available precursors ${ }^{1-14}$. The ability to improve upon existing preparations of known compounds, enable alternate retrosynthetic approaches to useful building blocks, and increase opportunities to explore novel chemical space outside of 'flatland' are all compelling reasons to develop new approaches to $\mathrm{N}$-heterocycles ${ }^{15-20}$. Piperidines rank as the most prominent $N$-heterocyclic pharmacophore in current drugs on the market, appearing in $~ 55 \%$ of all FDA-approved drugs containing at least one $N$-heterocycle, as well as in numerous bioactive natural products $^{3}$. Convergent methods that unite multiple reactive fragments, particularly hetero-[4+2] cycloadditions, deliver substituted dehydropiperidines in enantioenriched form ${ }^{21-31}$; however, critical substrate and/or catalyst control over regio- and stereoselectivity is challenging and often results in narrow scope. Traditional preparations of stereodefined piperidines using intramolecular $\mathrm{S}_{\mathrm{N}} 2$-type reactions require selective installation of functional groups prior to ring closure, resulting in lower efficiency, modularity, and step economy as the desired target's complexity increases ${ }^{3}$. A less common approach is to engage an aziridine and a simple coupling partner in a stereocontrolled, and ideally stereospecific, ring expansion reaction.

Aziridines are an ideal starting material for conversion into larger nitrogenated heterocycles. They are easily accessible from a variety of alkenes by nitrene transfer or from simple manipulations of epoxides. In addition, methods for asymmetric aziridination enable these strained rings to be prepared with substantial stereochemical and substitutional complexity ${ }^{32-36}$. An attractive feature of aziridines is their $\sim 26 \mathrm{kcal} \mathrm{mol}^{-1}$ of ring strain, ensuring a favorable thermodynamic driving force for ring-opening. Figure 1 illustrates a selection of transition metalcatalyzed aziridine expansions that furnish 4-7 membered $N$ heterocycles ${ }^{37-48}$. For example, Alper and others have achieved metal-catalyzed carbonylations of aziridines to yield valuable $\beta$-lactams, although good regioselectivity depends on the substitution pattern of the three-membered ring ${ }^{45}$. Njardarson has described a series of $\mathrm{Cu}$-catalyzed transformations of aziridines to pyrrolidines and related rings; while these reactions are often stereospecific, they are largely limited to intramolecular examples $^{40-42}$. Scattered examples describing the conversion of aziridines to piperidines, dehydropiperidines, and azepines (Fig. 1a) are known, but these reactions are also intramolecular or have limited scope ${ }^{44,46,47}$. In contrast, we were encouraged by Rowlands report of a single example of the formation of a dehydropiperidine in $21 \%$ yield (Fig. $1 \mathrm{~b}$ ) from a vinylaziridine ${ }^{49}$. This reaction presumably occurs through intramolecular formation of an aziridinium ylide, followed by [2,3]-rearrangement; however, only one invertomer undergoes the desired cyclization. The low yield is ascribed to the required coplanarity of the anion and the vinyl group; if the ylide forms with the opposite stereochemistry at nitrogen, $[1,5]$-hydrogen shifts and other decomposition ${ }^{50}$ pathways compete with productive ring expansion.

As noted in Fig. 1, aziridines must often be highly engineered to achieve effective ring expansions. In particular, inclusion of an adjacent vinyl group provides the kinetic impetus to drive successful metal-mediated isomerizations and other functionalizations ${ }^{39-41,44,46,47}$. In contrast, utilizing unbiased aziridines for stereocontrolled expansions to larger $N$-heterocycles can be challenging, as epimerization or racemization of the aziridine must be avoided to successfully relay stereochemical information at $s p^{3}$ stereocenters to the product with excellent fidelity ${ }^{51-54}$. Despite these difficulties, the ease of aziridine preparation and their strain-loaded reactivity make them attractive scaffolds for the discovery of new reactivity $32-36$.

We previously leveraged the unusual strain $(\sim 42 \mathrm{kcal} / \mathrm{mol})$ in methyleneaziridine $\mathbf{1 a}$ to achieve a formal [3+1] reaction to furnish methyleneazetidine 1d upon exposure to rhodium-supported

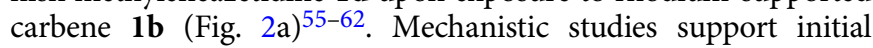
formation of the aziridinium ylide 1c, which subsequently undergoes a highly asynchronous, concerted [2,3]-Stevens rearrangement to form $1 \mathbf{1}^{63}$. The complete transfer of the chirality in 1a-d provides further experimental evidence to support this
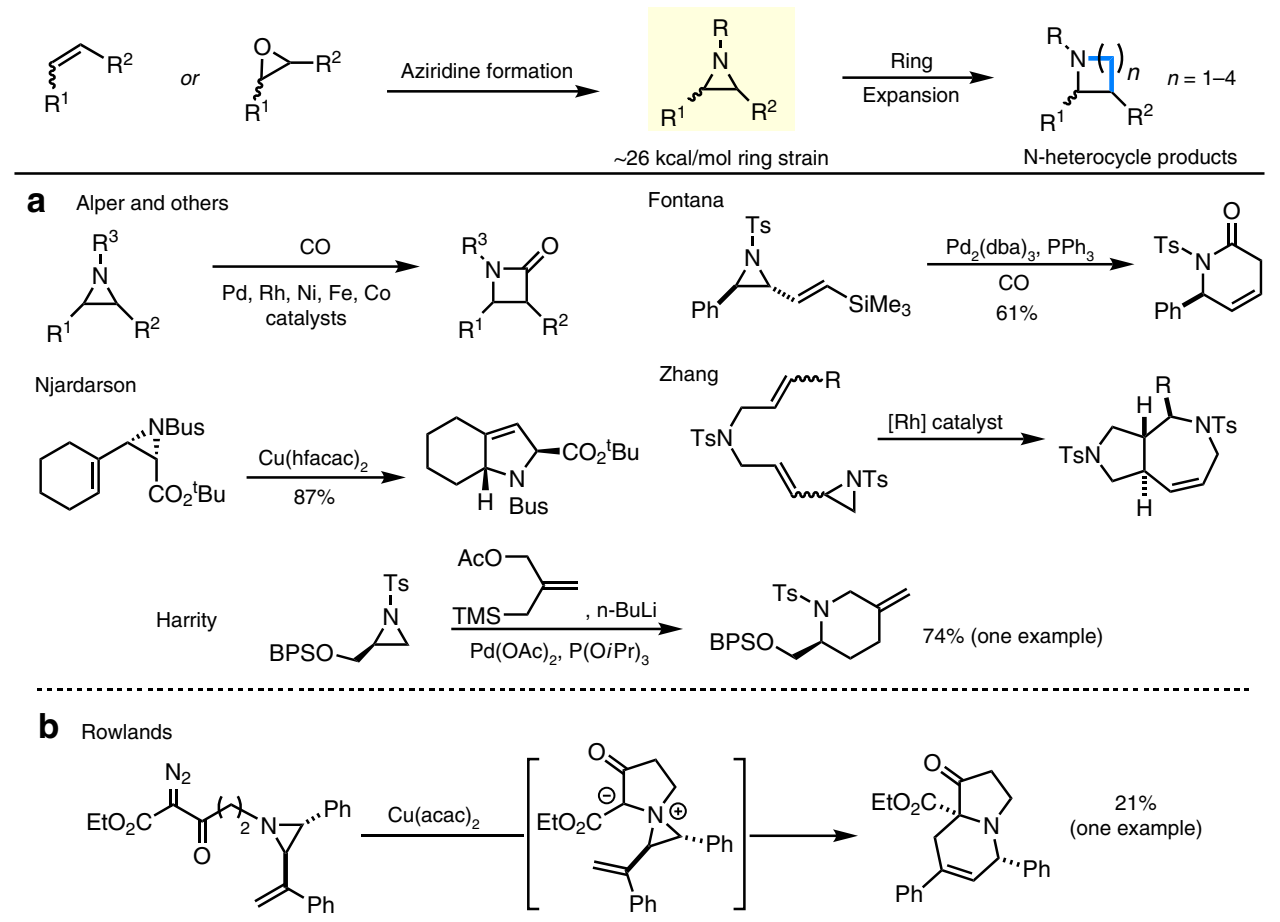

Fig. 1 Transformations of aziridines to $\mathbf{N}$-heterocycles. a Typical transition metal-catalyzed ring expansions. $\mathbf{b}$ Cu-catalyzed aziridine ring expansion through the intermediacy of an aziridinium ylide. 


\section{Previous work: Competing reaction pathways for aziridinium ylide intermediates}

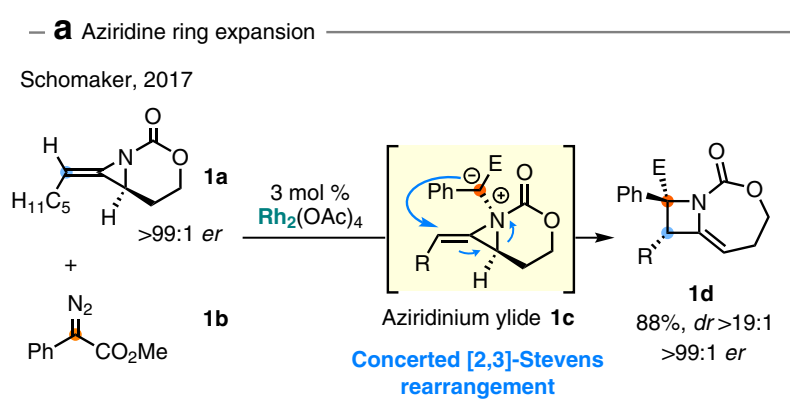

\section{- b Cheletropic extrusion}
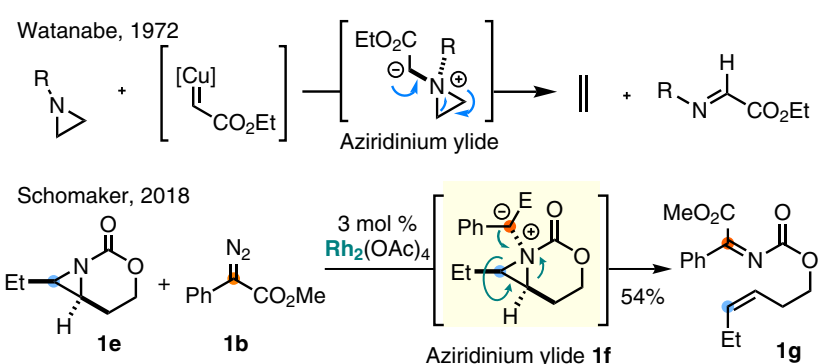

Aziridinium ylide

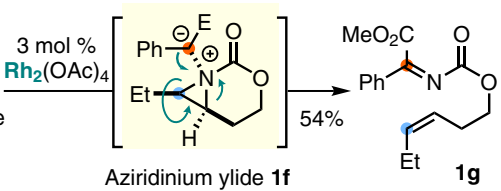

。

C This work: Formal [3+3] expansions of aziridines to dehydropiperidines<smiles>[R]C1[C@@H]2CCOC(=O)N12</smiles><smiles>[R]C=CC(=N)OC</smiles>

$1 \mathbf{i}$

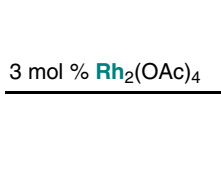

$a^{2}$

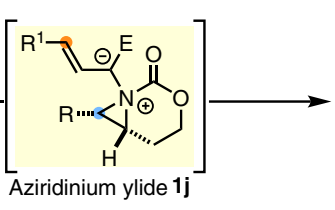

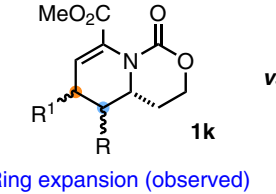

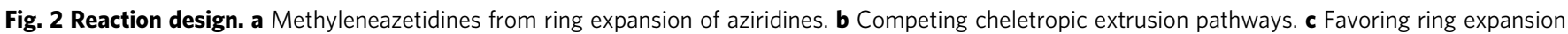
over cheletropic extrusion for the synthesis of dehydropiperidines.

mechanism. This efficient transformation, which forms new $\mathrm{C}-\mathrm{C}$ and $\mathrm{C}-\mathrm{N}$ bonds and two adjacent stereocenters in a stereospecific intermolecular two-fragment coupling, prompted us to undertake further studies of aziridinium ylides to extend the scope to unbiased aziridines. Unfortunately, removing the exocyclic alkene of $\mathbf{1 a}$ in 1e (Fig. 2b) gave only cheletropic extrusion with $\mathbf{1 b}$ to furnish $\mathbf{~} \mathbf{g}$, a pathway also observed by Watanabe in $\mathrm{Cu}$-catalyzed reaction of aziridines with ethyldiazoacetate ${ }^{50}$. We reasoned appending a vinyl group to the carbene precursor li (Fig. 2c) could facilitate the desired ring expansion of aziridinium ylide $\mathbf{1 j}$ $\mathbf{k}$ over competing cheletropic extrusion to 11 . This transformation represents a net [3+3] annulation of a vinyl carbenoid and a bicyclic aziridine; depending on the mechanism, transfer of stereochemical information from the aziridine to the dehydropiperidine with good fidelity could be envisaged. Herein, we report an attractive strategy to assemble stereochemically complex and highly substituted dehydropiperidines via an intermolecular ring expansion between simple bicyclic aziridines and Rh-supported vinyl carbenes. The intermediacy of an unusual aziridinium ylide species is followed by a stereospecific rearrangement that secures access to enantioenriched products.

\section{Results}

Scope of the $[3+3]$ ring expansion. To our delight, reaction of cis-alkene-derived aziridine 2a (Table 1) with Davies' styrenyl diazoacetate $^{64} \mathbf{3 a}$ under dirhodium catalysis produced $\mathbf{4 a a}$ in $75 \%$ yield and in excellent $>19: 1$ diastereoselectivity. Optimization of conditions for the $[3+3]$ aziridine ring expansion revealed the dirhodium paddlewheel complex $\mathrm{Rh}_{2}(\mathrm{OAc})_{4}$ was the superior catalyst using slow addition of the vinyl diazoacetate (see the Supplementary Information for further details). With these conditions in hand, the aziridine scope was further explored using 3a as the vinyl carbene precursor. Linear alkyl groups on aziridines 2a-d, including benzyl, methyl, ethyl, and $n$-butyl, gave good yields of the products 4aa-da in high $d r .{ }^{1} \mathrm{H}$ NMR spectroscopy indicated a $d r$ of at least $>19: 1$ for the dehydropiperidines, with only trace amounts of the presumed diastereomers noted. Increasing the bulk of the substituent on the aziridine to an isopropyl group in $\mathbf{2 e}$ furnished $\mathbf{4}$ ea in $71 \%$ yield and excellent $d r$. Alkyl chloride and ether functionalities were also well tolerated to deliver dehydropiperidines 4fa and 4ga. Alkyl substitution $\alpha$ to the carbamate tether in $2 \mathbf{h}(d r>19: 1)$ gave a $74 \%$ yield of 4 ha as a single diastereomer. Aziridine 2i, unsubstituted at the terminal carbon, gave $4 \mathbf{i a}$ in $67 \%$ yield and $>19: 1 d r$. Finally, it was not necessary to have the carbamate contained in a six-membered ring, as the [5.3]-bicyclic aziridine $2 \mathbf{j}\left(\mathrm{R}^{1}=\mathrm{Et}, n=0\right)$ gave the [5.6]-bicyclic ring $4 \mathbf{j a}$ in $42 \%$ yield and in $>19: 1 d r$.

We next examined the scope of the carbene precursor using ethyl-substituted aziridine $\mathbf{2 c}$ (Table 1). The impact of the electronics of a series of phenyl-substituted diazo acetates $3 \mathbf{a}-\mathbf{f}$ was investigated first. Similar yields were obtained for $\mathbf{4 c a}$ and 4cb-cc, irrespective of whether the diazoester carbene precursor contains electron-donating or neutral substituents, highlighting there is little effect of the styrene electronics on the reaction outcome. A single-crystal X-ray structure of $4 \mathrm{cc}$ established the relative stereochemical configuration of the heterocycle product (see expansion for 4cc and the Supplementary Information for further details), corroborating nOe studies. Moving the $\mathrm{Br}$ to the meta position in 3d resulted in a similar $79 \%$ yield of $\mathbf{4} \mathbf{c d}$. Diazoester 3e, bearing a strongly electron-withdrawing trifluoromethyl group, gave a $69 \%$ yield of $4 \mathrm{ce}$, also in good $d r$, providing a convenient way to introduce valuable fluorines into the dehydropiperidine products.

Carbene transfer of the naphthyl-substituted $\mathbf{3 f}$ provided $\mathbf{4 c f}$ in similar yield and $d r$ as compared with $\mathbf{4 c a}$. It was not necessary to employ a styrenyl-derived diazoester, as a series of $\beta$-alkylsubstituted diazoesters $\mathbf{3 g}$-i all resulted in good yields of unsaturated piperidines $\mathbf{4} \mathbf{c g}-\mathbf{c i}$ as single diastereomers as determined by ${ }^{1} \mathrm{H}$ NMR. The furan-substituted $\mathbf{3 j}$ gave $\mathbf{4} \mathbf{c j}$ in only $14 \%$ isolated yield, as these oxygen heterocycles have been reported to be reactive in the presence of metal-supported carbenoids ${ }^{65,66}$. Bulking up the methyl ester on the diazoester to a cyclohexyl ester was also successful, producing 4ck in 56\% yield and $>19: 1 d r$.

Computational studies of the mechanism. The difficulty of studying carbene transfer using traditional kinetics, particularly when slow addition is required, led us to turn to DFT calculations (computational details are in the Supplementary Information and Supplementary Data 1) to gain more insight into the mechanism of the ring expansion (Fig. 3). The reaction of the methylsubstituted aziridine $\mathbf{2 b}$ and the $\left[\mathrm{Rh}_{2}\right]$-carbenoid derived from diazoacetate 3a to furnish $\mathbf{4} \mathbf{b a}$ was explored computationally. Nucleophilic attack of the aziridine nitrogen atom on the carbon 
Table 1 Scope of the aziridine and diazoester in Rh-catalyzed ring expansions to dehydropiperidines.

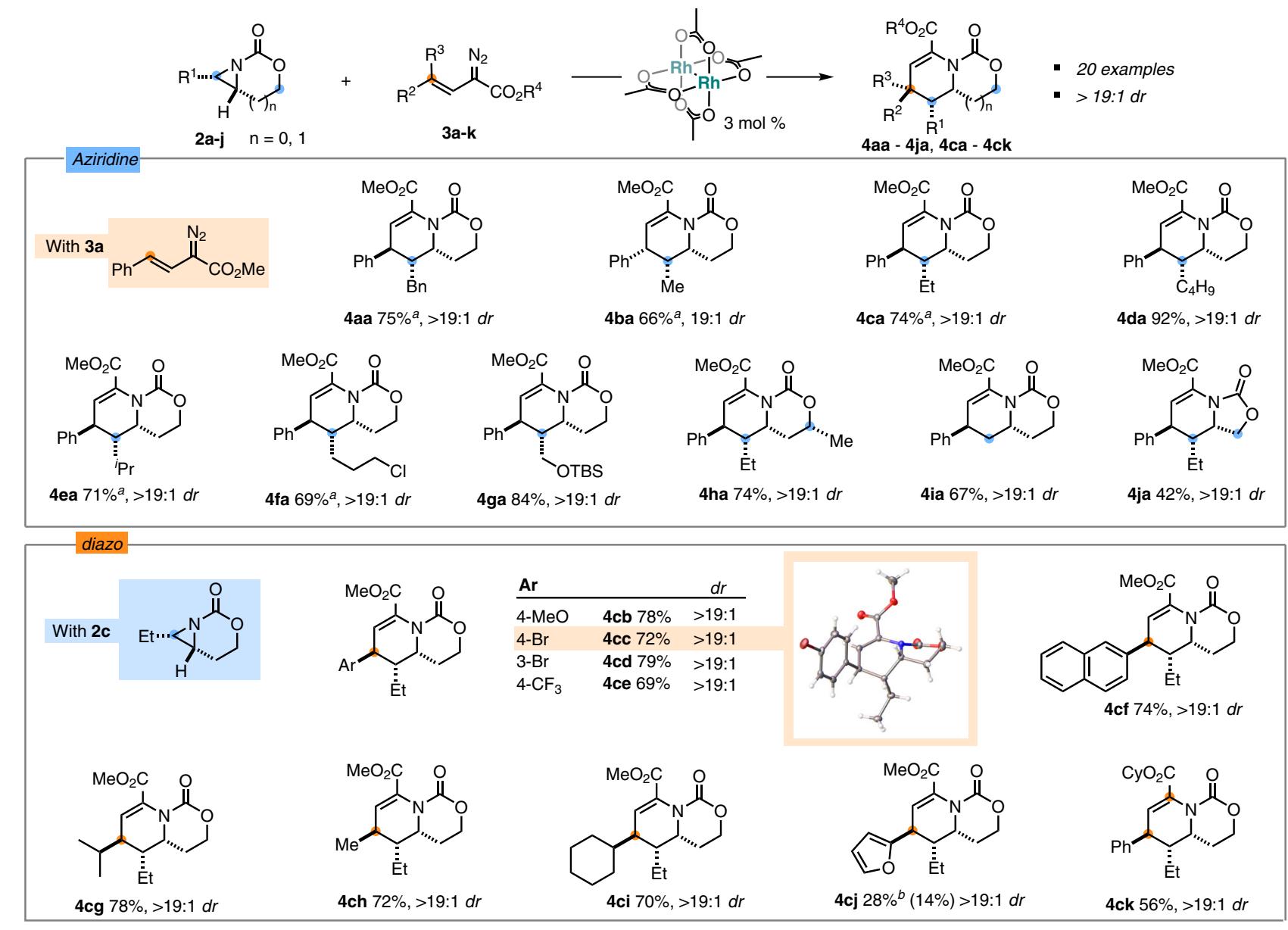

aConditions: 3 mol\% $\mathrm{Rh}_{2}(\mathrm{OAc})_{4}, 0.05 \mathrm{M} \mathrm{CH}_{2} \mathrm{Cl}_{2}$, rt, slow addition of diazoacetate as a solution in $\mathrm{CH}_{2} \mathrm{Cl}_{2}$.

bNMR yield.

of the Rh-supported carbenoid occurs as the first step to form aziridinium ylide INT1 via transition state TS1 ${ }^{62,63}$. Then, barrierless and exergonic dissociation of the dirhodim catalyst from the nitrogen produces zwitterion INT2, where the negative charge is fully delocalized into the allylic system (Fig. 3b).

Two fates were envisaged for INT2. In the first case, INT2 forms azadiene INT3 through a cheletropic extrusion (via TS2), followed by a concerted aza-Diels-Alder cycloaddition (via TS3) to furnish $\mathbf{4} \mathbf{b a}$. However, subjecting enantioenriched $(S, R)-\mathbf{2} \mathbf{a}^{67}$ to the standard reaction conditions resulted in transfer of the chirality to $(R, R, R)$-4aa with good fidelity (Fig. 3b). This effectively rules out cheletropic extrusion, followed by aza-Diels-Alder reaction, as the operative mechanism for formation of the dehydropiperidine. We also considered that Stevens rearrangements involving ammonium ylides are occasionally reported to proceed through diradical intermediates ${ }^{68}$; however, the chirality transfer from $(S, R)-\mathbf{2 a}$ to $(R, R, R)$-4aa suggests that a diradical pathway cannot be operative in the absence of a solvent cage.

An alternate fate for the aziridinium ylide INT2 is suggested by the computations in Scheme 3 and involves a rare pseudo-[1,4]sigmatropic rearrangement of INT2 via TS2'. This pathway has never been observed for an aziridinium ylide; however, a single example of a $[1,4]$-rearrangement of an ammonium benzylide has been reported ${ }^{69,70}$. According to our calculations, this path proceeds with a lower barrier than the competing cheletropic extrusion $\left(\Delta \Delta \mathrm{G}^{\neq}=5.3 \mathrm{kcal} / \mathrm{mol}\right)$. In addition, this mechanism would be expected to directly parlay absolute and relative stereochemical information from the aziridine into the product, supporting our experimental observations of chirality transfer from $(S, R)-\mathbf{2 a}$ to $(R, R, R)-\mathbf{4} \mathbf{a a}^{62,63}$. Zwitterion INT3' could not be located on the potential energy surface. Indeed, intrinsic reaction calculations (IRCs) starting from TS2' show the final closing of the $\mathrm{C}-\mathrm{C}$ bond to form the piperidine exists on a plateau-like energy pathway, where ring closure only begins to occur following completion of the $\mathrm{C}-\mathrm{N}$ bond rupture.

The retention of stereochemistry at the internal aziridine carbon $\mathrm{C} 1$ of $\mathbf{2 b}$ in $\mathbf{4} \mathbf{b a}$ provided an interesting clue to the exact nature of the rearrangement of INT2 to $4 \mathbf{b a}$. One possibility involves intramolecular $\mathrm{S}_{\mathrm{N}} 2$ attack of the benzylic carbon on $\mathrm{C} 1$ of INT2 (Fig. 3a) to close the ring. However, it is unlikely a $\pi$ orbital on the benzylic carbon can overlap effectively with the $\sigma^{*}$ of the aziridinium ylide to enable $\mathrm{S}_{\mathrm{N}} 2$. More importantly, $\mathrm{S}_{\mathrm{N}} 2$ attack at $\mathrm{C} 1$ would invert the stereochemistry at $\mathrm{C} 1$, which is ruled out by the X-ray crystal structure of $4 \mathbf{c c}$. Rather, we propose ring expansion occurs via an unusual stereoretentive nucleophilic substitution; examples of this rare mechanism 


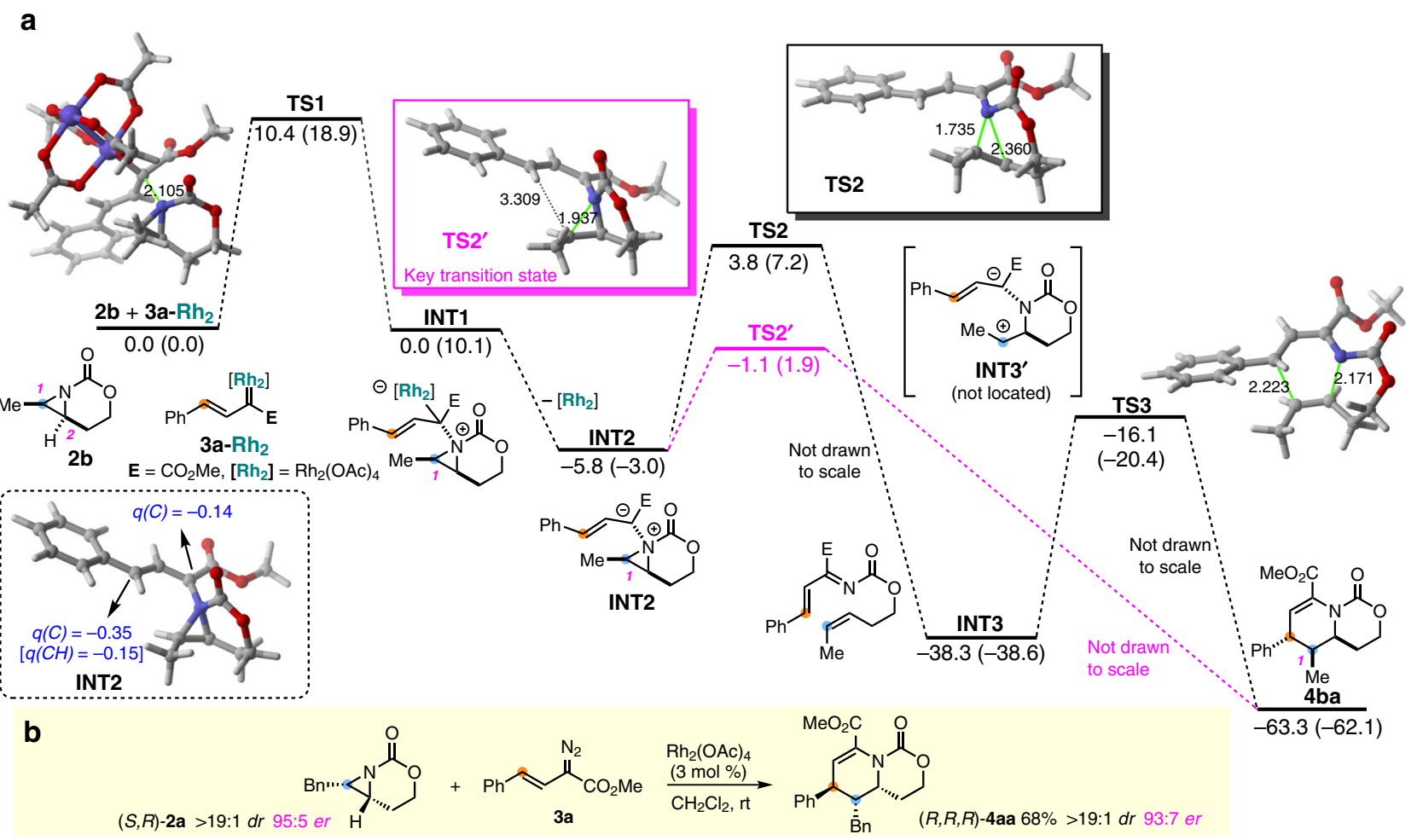

Fig. 3 Mechanistic studies of the [3 +3 ] ring expansion. a Computed reaction profile for the process involving $\mathbf{2} \mathbf{b}$ and $\mathbf{R} \mathbf{h}_{\mathbf{2}}$-bound carbene $\mathbf{3 a}$ - $\mathbf{R} \mathbf{h}_{\mathbf{2}}$. Relative free energies $(\Delta \mathrm{G}$, computed at $298.15 \mathrm{~K}$ and $1 \mathrm{M})$ and bond distances are in $\mathrm{kcal} / \mathrm{mol}$ and $\AA$, respectively. All data are computed at the $\mathrm{SMD}\left(\mathrm{CH}_{2} \mathrm{Cl}{ }_{2}\right)-$ B3LYP-D3/def2-SVP level. Values within parentheses are computed at the SMD $\left(\mathrm{CH}_{2} \mathrm{Cl}_{2}\right)-\mathrm{B} 3 \mathrm{LYP}-\mathrm{D} 3 / \mathrm{def} 2-\mathrm{TZVPP} / / \mathrm{SMD}\left(\mathrm{CH}_{2} \mathrm{Cl} \mathrm{I}_{2}\right)-\mathrm{B} 3 \mathrm{LYP}-\mathrm{D} 3 / \mathrm{def} 2-\mathrm{SVP}$ level of theory. $\mathbf{b}$ Stereochemical retention experiment.

include the chlorination of secondary alcohols with thionyl chloride $\left(\mathrm{S}_{\mathrm{N}} \mathrm{i}\right)$ and benzylic substitution in supramolecular cavities $^{71,72}$. Computations also support a stereoretentive ' $\mathrm{S}_{\mathrm{N}} 1$ like' mechanism. First, the lower energy TS2' is comprised mainly of $\mathrm{C}-\mathrm{N}$ bond breakage at the external $\mathrm{C} 1-\mathrm{N}$ bond, which elongates to $1.937 \AA$. This contrasts to the bond-breaking sequence in the disfavored TS2, where the internal bicyclic $\mathrm{C} 2-\mathrm{N}$ bond shows more elongation at $2.360 \AA$, as compared with the $\mathrm{C} 1-\mathrm{N}$ bond $(1.735 \AA)$. Thus, even though both TS2 and TS2 ${ }^{\prime}$ can be described as relatively low-barrier, early transition states, the extent to which the $\mathrm{C}-\mathrm{N}$ bond breaks appears biased. Second, and consistent with our experimental results, TS2' predicts that ring opening of the $\mathrm{C} 1-\mathrm{N}$ aziridine bond and the subsequent $\mathrm{C}-\mathrm{C}$ bond formation must proceed with retention. This is largely due to the stereochemical relationship established between the nitrogen and the carbon substituents of the aziridine during formation of the aziridinium ylide; the carbamate tether controls this stereochemistry and likely plays a key role in restricting the conformational flexibility of the intermediates. Thus, the Me-bearing $\mathrm{C} 1$ of the original aziridine 2b is essentially a full carbocation, with nearly complete C-N rupture in TS2 $^{\prime}$ just prior to stereoretentive ring closure.

Chirality transfer. The synthetic utility of the sequential nitrene/ carbene transfer reaction could be amplified by running it in tandem with asymmetric alkene aziridination to form enantioenriched piperidines over two steps. In 2017, we disclosed an asymmetric aziridination protocol using silver bisoxazoline complexes to enact intramolecular aziridination of homoallylic carbamate esters to achieve high enantioselectivities with a costeffective catalyst ${ }^{67}$. Application of our asymmetric aziridination to the carbamate of (3Z)-3-penten-5-phenyl-1-ol gave enantioenriched $(S, R)-\mathbf{2 a}{ }^{67}$ in $95: 5$ er (Figs. 3b and 4a). Treatment of $(S, R)-2 \mathbf{a}$ under the standard reaction conditions gives $(R, R, R)-\mathbf{4 a a}$ with minimal loss of ee. Alternatively, a single catalyst could be used to accomplish the sequential nitrene/carbene transfer. Preparation of the allylic $\mathrm{N}$-tosyloxycarbamate ester $\mathbf{5}$, according to the method described by Lebel et al. ${ }^{73}$, followed by treatment with $\mathrm{Rh}_{2}(\mathrm{OAc})_{4}$ and $\mathrm{K}_{2} \mathrm{CO}_{3}$ generated the intermediate [5.3]-bicyclic aziridine. Filtration and solvent exchange, followed by slow addition of $\mathbf{3 a}$, gave the unsaturated piperidine $4 \mathbf{j a}$ in $54 \%$ and $>19: 1 d r$. Efforts to identify chemo- and enantioselective Rhcatalyzed aziridination catalysts are underway to secure access to these valuable heterocycles in one pot with good $e e$.

Functionalization of dehydropiperidine products. Further functionalization of the unsaturated piperidine $4 \mathrm{ca}$ provides fully substituted, stereochemically rich piperidines in just two steps from the bicyclic aziridine. Indeed, treatment of $\mathbf{4} \mathbf{c a}$ with a higher order cuprate furnished 6 in 57\% yield and >19:1 $d r$ through a diastereoselective conjugate addition reaction; the relative stereochemistry was verified by both NOE and ${ }^{1} \mathrm{H}$ NMR-coupling constants (Fig. 4b, see the Supplementary Information for details) ${ }^{74-76}$. In an initial effort to expand the conjugate addition reaction to include other heteroatom nucleophiles, we found treatment of $4 \mathrm{ca}$ with DBU and various nucleophiles did not furnish a conjugate addition product, but rather produced styrene 7 in $71 \%$ yield and excellent $d r$ (Fig. 4b). Further treatment of 7 with $m$ CPBA yielded epoxide 8 in equally good yield and $d r$. Furthermore, inspired by MacMillan and coworkers $^{77}, 4 \mathrm{ca}$ was found to undergo a radical Michael addition with Boc-protected tryptophan 9 to yield fully elaborated piperidine $\mathbf{1 0}$ in $32 \%$ yield as a single diastereomer. Although the 
a Sequential enantioselective nitrene/carbene

-or-

Rh-catalyzed one-pot nitrene/carbene transfer
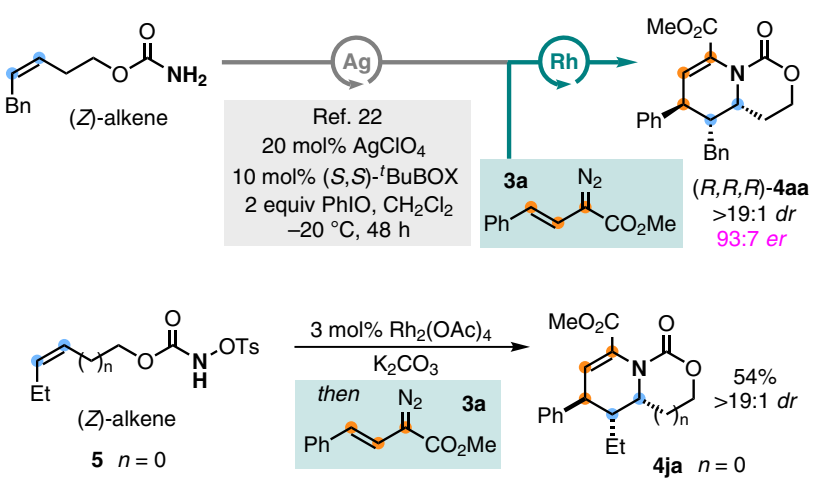

$5 n=0$
C Mild functionalization of biomolecules

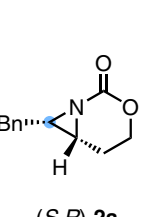

\section{$(S, R)-\mathbf{2 a}$}

$>19: 1 d r$

$97: 3$ er

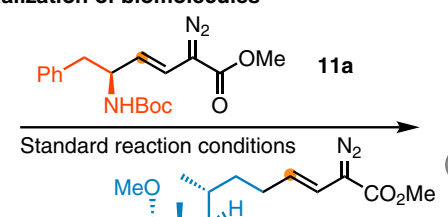

$11 \mathrm{~b}$<smiles>COC(=O)C1=CC(O)[C@H](Br)[C@@H]2CCOC(=O)N12</smiles>

$12 a-b$

$11 \mathrm{~b}$ 'OMe Cholic acid derivative

Phenylalanine derivative<smiles>COC1=C[C@H](C(N)Cc2ccccc2)[C@H](Br)[C@@H]2CCOC(=O)N12</smiles>

12a $57 \%$ $d r>19: 1$

b Derivatization to chiral piperidines<smiles>CC[C@H]1C2CCOC(=O)N2C(C(C)=O)C2OC21c1ccccc1</smiles>

$83 \%, d r>19: 1$ 2.8 equiv $m C P B A$ $\mathrm{CH}_{2} \mathrm{Cl}_{2}$, reflux<smiles>[3H]C[C@H]1COC(=O)N2C(C(C)=O)C=C(c3ccccc3)[C@H](CC)C12</smiles>

$71 \%, d r>19: 1$

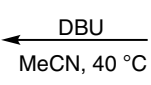

$\mathrm{MeCN}, 40^{\circ} \mathrm{C}$<smiles>CI</smiles>

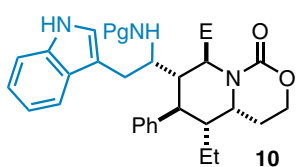

$\mathrm{Pg}=\mathrm{Boc}, \mathrm{E}=\mathrm{CO}_{2} \mathrm{Me}$

$32 \%, 45 \%$ BRSM $d r>19: 1$

Fig. 4 Tandem nitrene/carbene chemistry and derivatization of products. a Streamlining the nitrene/carbene transfer sequence. $\mathbf{b}$ Late-stage functionalization of complex molecules. c Further derivatization of dehydropiperidines.

yield was modest, this transformation rapidly builds complexity in two steps from a simple aziridine.

Finally, the mild reaction conditions and the transfer of the stereochemical information in the aziridine $(S, R)$-2a to $(R, R, R)$ 4aa with good fidelity promoted us to explore the potential of this chemistry to append biomolecules to our unsaturated piperidine scaffolds. D-Phenylalanine and cholic acid were transformed into suitable diazoesters 11a and 11b (Fig. 4c), then subjected to treatment with $(S, R)-\mathbf{2 a}(94 \%$ ee $)$ under the standard reaction conditions. The products $\mathbf{1 2 a}$ and $\mathbf{1 2 b}$ were obtained in good yields, with excellent diastereoselectivities and enantiomeric ratios. We envisage this strategy could be effectively applied to explorations of new bioactive chemical space uncovered through fragment-based screening approaches.

In conclusion, aziridinium ylides, accessed in high diastereoselectivity from the intermolecular reaction of simple aziridines with metal-bound vinyl carbenes, are shown to be efficient intermediates for the conversion of small ring heterocycles to complex piperidines, a privileged motif in bioactive compounds. DFT computations, in tandem with transfer of chirality experiments, revealed that the ylides undergo a concerted, asynchronous, pseudo-[1,4]-sigmatropic rearrangement to yield products in high diastereoselectivity and with retention of ee installed in the aziridine precursor. Surprisingly, this chemistry bypasses deleterious cheletropic extrusion using unbiased aziridines to give synthetically useful yields of $N$-heterocycles. In addition, this mechanism proceeds with retention at the $\mathrm{C}-\mathrm{C}$ bond, a unique consequence of the $\mathrm{S}_{\mathrm{N}} 1$-like closing of the vinyl anion tether. We anticipate this report will spur further research into the reactivity of both aziridinium ylides and other onium ylides derived from small-ring heterocycles.

\section{Methods}

General procedure for the dehydropiperidine synthesis. A flame-dried round bottom flask is placed under nitrogen and charged with $\mathrm{Rh}_{2}(\mathrm{OAc})_{4}(0.03$ equiv), followed by a solution of the aziridine $\left(0.1 \mathrm{M}\right.$ in dry $\left.\mathrm{CH}_{2} \mathrm{Cl}_{2}\right)$. Upon the addition of the aziridine substrate, a color change of green to purple is observed. To this mixture is added a solution of the diazoester compound (1.2 equiv diluted to $0.1 \mathrm{M}$ in $\mathrm{CH}_{2} \mathrm{Cl}_{2}$ ) dropwise over $2 \mathrm{~h}$ using a syringe pump. The conversion is checked by TLC and ${ }^{1} \mathrm{H}$ NMR after the addition of the diazoester is complete; once all the starting material is consumed, the reaction mixture is concentrated and loaded directly onto a silica gel column for purification by chromatography using a gradient of $0-50 \% \mathrm{EtOAc} /$ hexanes.

\section{Data availability}

The authors declare that all data supporting the findings of this study are available within the paper and its Supplementary Information and Supplementary Data 1 files, including experimental procedures, computational details, and characterization data for all new compounds. The crystallographic data for Compound $4 \mathbf{c c}$ are available in the CCDC repository https://www.ccdc.cam.ac.uk/solutions/csd-system/components/csd/ under deposition number 1921208.

Received: 7 October 2019; Accepted: 21 February 2020;

Published online: 09 March 2020

\section{References}

1. O’Hagan, D. Pyrrole, pyrrolidine, pyridine, piperidine and tropane alkaloids. Nat. Prod. Rep. 17, 435-446 (2000) 
2. Chen, Q., Gao, J., Zou, G. A., Xin, X. L. \& Aisa, H. A. Piperidine alkaloids with diverse skeletons from Anacyclus pyrethrum. J. Nat. Prod. 81, 1474-1482 (2018).

3. Vitaku, E., Smith, D. T. \& Njardarson, J. T. Analysis of the structural diversity, substitution patterns, and frequency of nitrogen heterocycles among U.S. FDA-approved pharmaceuticals. J. Med. Chem. 57, 10257-10274 (2014).

4. Taylor, R. D., MacCoss, M. \& Lawson, A. D. Rings in drugs. J. Med. Chem. 57, 5845-5859 (2014).

5. Baumann, M. \& Baxendale, I. R. An overview of the synthetic routes to the best-selling drugs containing 6-membered heterocycles. Beilstein J. Org. Chem. 9, 2265-2319 (2013)

6. Lamberth, C. Heterocyclic chemistry in crop protection. Pest Manag. Sci. 69, 1106-1114 (2013).

7. Nauen, R. \& Jeshke, P. Neonicotinoids-from zero to hero in insecticide chemistry. Pest Manag. Sci. 64, 1084-1098 (2008).

8. Lamberth, C. Pyrimidine chemistry in crop protection. Heterocycles $\mathbf{6 8}$, 561-603 (2006)

9. Lamberth, C. Pyrazole chemistry in crop protection. Heterocycles 71, 1467-1502 (2007).

10. Di, NisioM., Middeldorp, S. \& Büller, H. R. Direct thrombin inhibitors. $N$. Engl. J. Med. 353, 1028-1040 (2005).

11. Ito, T., Otsuki, M. \& Nishino, T. In vitro antibacterial activity of Q-35, a new fluoroquinolone. Antimicrob. Agents Chemother. 36, 1708-1714 (1992).

12. Brüning A. Analysis of Nelfinavir-Induced endoplasmic reticulum stress. In Methods in Enzymology. Academic Press 491, 127-142 (2011).

13. Børup, C., Meidahl, B., Petersen, I. M., Vangtorp, A. \& le Fèvre Honoré, P. An early clinical Phase II evaluation of Paroxetine, a new potent and selective 5HT-uptake inhibitor in patients with depressive illness. Pharmacopsychiatry 15, 183-186 (1982).

14. Lund, J., Lomholt, B., Fabricius, J., Christensen, J. A. \& Bechgaardl, E. Paroxetine: pharmacokinetics, tolerance and depletion of blood 5-HT in man. Acta Pharmacol. Toxicol. 44, 289-295 (1979).

15. Scannell, J. W., Blanckley, A., Boldon, H. \& Warrington, B. Diagnosing the decline in pharmaceutical R\&D efficiency. Nat. Rev. Drug Discov. 11, 191-200 (2012).

16. Barker, A., Kettle, J., Nowak, T. \& Pease, J. Expanding medicinal chemistry space. Drug Discov Today 18, 298-304 (2013).

17. Lovering, F., Bikker, J. \& Humblet, C. Escape from Flatland: Increasing saturation as an approach to improving clinical success. J. Med. Chem. 52, 6752-6756 (2009).

18. Brown, D. G. \& Bostrom, J. An analysis of past and present synthetic methodologies on medicinal chemistry: Where have all the new reactions gone? J. Med. Chem. 59, 4443-4458 (2016).

19. Doak, B. C., Zheng, J., Dobrizsch, D. \& Kihlberg, J. How beyond Rule of 5 drugs and clinical candidates bind to their targets. J. Med. Chem. 59 2312-2327 (2016).

20. Lovering, F. Escape from Flatland 2: complexity and promiscuity. Med. Chem. Commun. 4, 515-519 (2013).

21. Ma, C. et al. 1-Azadienes as regio- and chemoselective dienophiles in aminocatalytic asymmetric Diels-Alder reaction. Org. Lett. 15, 6206-6209 (2013).

22. Jarrige, L., Blanchard, F. \& Masson, G. Enantioselective organocatalytic intramolecular aza-Diels-Alder reaction. Angew. Chem. Int. Ed. 56, 10573-10576 (2017)

23. Wang, H., Zhou, W., Tao, M., Hu, A. \& Zhang, J. Functionalized tetrahydropyridines by enantioselective phosphine-catalyzed aza-[4+2] cycloaddition of N-sulfonyl-1-aza-1,3-dienes with vinyl ketones. Org. Lett. 19, 1710-1713 (2017).

24. He, M., Struble, J. R. \& Bode, J. W. Highly enantioselective azadiene Diels-Alder reactions catalyzed by chiral N-heterocyclic carbenes. J. Am. Chem. Soc. 128, 8418-8420 (2006).

25. Chu, J. C., Dalton, D. M. \& Rovis, T. Zn-catalyzed enantio- and diastereoselective formal [4+2] cycloaddition involving two electron-deficient partners: Asymmetric synthesis of piperidines from 1-azadienes and nitroalkenes. J. Am. Chem. Soc. 137, 4445-4452 (2015).

26. Bossharth, E., Desbordes, P., Monteiro, N. \& Balme, G. Palladium-mediated three-component synthesis of furo[2,3-b]pyridones by one-pot coupling of 3iodopyridones, alkynes, and organic halides. Org. Lett. 5, 2441-2444 (2003).

27. Shu, C. \& Liebeskind, L. S. Enantiocontrolled synthesis of 2,6-disubstituted piperidines by desymmetrization of meso- $\eta-(3,4,5)$ dihydropyridinylmolybdenum complexes. Application to the total synthesis of (-)-dihydropinidine and (-)-andrachcinidine. J. Am. Chem. Soc. 125, 2878-2879 (2003).

28. Fayol, A. \& Zhu, J. Synthesis of polysubstituted 4,5,6,7-tetrahydrofuro[2,3-c] pyridines by a novel multicomponent reaction. Org. Lett. 6, 115-118 (2004).

29. Zhu, W. et al. Multicomponent reactions for the synthesis of complex piperidine scaffolds. Angew. Chem. Int. Ed. 48, 5880-5883 (2009)
30. Jakubec, P., Cockfield, D. M., Helliwell, M., Raftery, J. \& Dixon, D. J. Stereoselective, nitro-Mannich/lactamization cascades for the direct synthesis of heavily decorated 5-nitropiperidin-2-ones and related heterocycles. Beilstein J. Org. Chem. 8, 567-578 (2012).

31. Kubota, K., Watanabe, Y., Hayama, K. \& Ito, H. Enantioselective synthesis of chiral piperidines via the stepwise dearomatization/borylation of pyridines. $J$ Am. Chem. Soc. 138, 4338-4341 (2016).

32. Katsuki, T. \& Martin, V. Asymmetric epoxidation of allylic alcohols: the Katsuki-Sharpless epoxidation reaction. Org. React. 48, 1-299 (2004).

33. Zhang, W., Loebach, J. L., Wilson, S. R. \& Jacobsen, E. N. Enantioselective epoxidation of unfunctionalized olefins catalyzed by salen manganese complexes. J. Am. Chem. Soc. 112, 2801-2803 (1990).

34. Katsuki, T. \& Sharpless, K. B. The first practical method for asymmetric epoxidation. J. Am. Chem. Soc. 102, 5974-5976 (1980).

35. Li, Z., Conser, K. R. \& Jacobsen, E. N. Asymmetric alkene aziridination with readily available chiral diimine-based catalysts. J. Am. Chem. Soc. 115, 5326-5327 (1993)

36. Evans, D. A., Faul, M. M., Bilodeau, M. T., Anderson, B. A. \& Barnes, D. M. Bis (oxazoline)-copper complexes as chiral catalysts for the enantioselective aziridination of olefins. J. Am. Chem. Soc. 115, 5328-5329 (1993).

37. Ghorai, M. K., Bhattacharyya, A., Das, S. \& Chauhan, N. Ring expansions of activated aziridines and azetidines in Synthesis of 4-to 7-membered heterocycles by ring expansion. Springer, 49-142, (2015).

38. Ghorai, M. K., Shukla, D. \& Bhattacharyya, A. Syntheses of chiral $\beta$-and $\gamma$ amino ethers, morpholines, and their homologues via nucleophilic ringopening of chiral activated aziridines and azetidines. J. Org. Chem. 77, 3740-3753 (2012)

39. Schomaker, J. M., Bhattacharjee, S., Yan, J. \& Borhan, B. Diastereomerically and enantiomerically pure 2,3-disubstituted pyrrolidines from 2,3-aziridin-1ols using a sulfoxonium ylide: a one-carbon homologative relay ring expansion. J. Am. Chem. Soc. 129, 1996-2003 (2007).

40. Ilardi, E. A. \& Njardarson, J. T. Ring expansions of vinyloxiranes, -thiiranes, and-aziridines: synthetic approaches, challenges, and catalytic success stories. J. Org. Chem. 78, 9533-9540 (2013).

41. Brichacek, M., Navarro Villalobos, M., Plichta, A. \& Njardarson, J. T. Stereospecific ring expansion of chiral vinyl aziridines. Org. Lett. 13, $1110-1113(2011)$

42. Mack, D. J. \& Njardarson, J. T. Recent advances in the metal-catalyzed ring expansions of three-and four-membered rings. ACS Catal. 3, 272-286 (2013)

43. D'hooghe, M. \& Ha, H. J. Synthesis of 4-to 7-membered heterocycles by ring expansion. in Topics in Heterocyclic Chemistry. Springer 41 (2016).

44. Provoost, O. Y., Hazelwood, A. J. \& Harrity, J. P. Pd-catalysed [3+3] annelations in the stereoselective synthesis of indolizidines. Beilstein J. Org. Chem. 3, https://doi.org/10.1186/1860-5397-3-8 (2007).

45. Piens, N. \& D'hooghe, M. Carbonylation of aziridines as a powerful tool for the synthesis of functionalized $\beta$-lactams. Eur. J. Org. Chem. 40, 5943-5960 (2017).

46. Feng, J.-J., Lin, T.-Y., Wu, H.-H. \& Zhang, J. Modular access to the stereoisomers of fused bicyclic azepines: Rhodium-catalyzed intramolecular stereospecific hetero-[5+2] cycloaddition of vinyl aziridines and alkenes. Angew. Chem. Int. Ed. 54, 15854-15858 (2015).

47. Aahman, J. \& Somfai, P. Aza-[2,3]-Wittig rearrangements of vinylaziridines. J. Am. Chem. Soc. 116, 9781-9782 (1994).

48. Clark, J. S. et al. Rearrangement of ammonium ylides produced by intramolecular reaction of catalytically generated metal carbenoids. Part 2. Stereoselective synthesis of bicyclic amines. J. Chem. Soc. Perkin Trans. 1, 3325 (2001).

49. Kentish Barnes, W. \& Rowlands, G. J. Studies on the [2,3]-Stevens rearrangement of aziridinium ions. Tetrahedron Lett. 45, 5347-5350 (2004).

50. Hata, Y. \& Watanabe, M. Fragmentation reaction of aziridinium ylides. Tetrahedron Lett. 46, 4659-4660 (1972)

51. Dolfen, J., Kenis, S., Van Hecke, K., De Kimpe, N. \& D’hooghe, M. Selective synthesis of functionalized trifluoromethylated pyrrolidines, piperidines, and azepanes starting from 1-tosyl-2-(trifluoromethyl) aziridine. Chem. Eur. J. 20, 10650-10653 (2014)

52. Coldham, I., Collis, A. J., Mould, R. J. \& Rathmell, R. E. Ring expansion of aziridines to piperidines using the aza-Wittig rearrangement. Tetrahedron Lett. 36, 3557-3560 (1995).

53. Vervisch, K., D’hooghe, M., Törnroos, K. W. \& De Kimpe, N. Synthesis of stereodefined piperidines from aziridines and their transformation into conformationally constrained amino acids, amino alcohols and 2,7diazabicyclo[3.3.1]nonanes. J. Org. Chem. 75, 7734-7744 (2010).

54. Jarvis, S. B. \& Charette, A. B. Synthesis of enantiopure substituted piperidines via an aziridinium ring expansion. Org. Lett. 13, 3830-3833 (2011).

55. Boralsky, L. A., Marston, D., Grigg, R. D., Hershberger, J. C. \& Schomaker, J. M. Allene functionalization via bicyclic methyleneaziridines. Org. Lett. 13, 1924-1927 (2011) 
56. Rigoli, J. W. et al. 1,4-Diazaspiro[2.2]pentanes as a flexible platform for the synthesis of diamine-bearing stereotriads. J. Org. Chem. 77, 2446-2455 (2012).

57. Adams, C. S., Boralsky, L. A., Guzei, I. A. \& Schomaker, J. M. Modular functionalization of allenes to aminated stereotriads. J. Am. Chem. Soc. 134, 10807-10810 (2012)

58. Adams, C. S., Grigg, R. D. \& Schomaker, J. M. Complete stereodivergence in the synthesis of 2-amino-1,3-diols from allenes. Chem. Sci. 5, 3046-3056 (2014).

59. Burke, E. G. \& Schomaker, J. M. Oxidative allene amination for the synthesis of azetidin-3-ones. Angew. Chem. Int. Ed. 54, 12097-12101 (2015).

60. Gerstner, N. C., Adams, C. S., Tretbar, M. \& Schomaker, J. M. Stereocontrolled syntheses of seven-membered carbocycles by tandem allene aziridination/[4+3] reaction. Angew. Chem. Int. Ed. 128, 13434-13437 (2016).

61. Adams, C. S., Weatherly, C. D., Burke, E. G. \& Schomaker, J. M. The conversion of allenes to strained three-membered heterocycles. Chem. Soc. Rev. 43, 3136-3316 (2014).

62. Schmid, S. C., Guzei, I. A. \& Schomaker, J. M. A stereoselective [3+1] ring expansion for the synthesis of highly substituted methylene azetidines. Angew. Chem. Int. Ed. 56, 12229-12233 (2017).

63. Schmid, S. C., Guzei, I., Fernandez, I. \& Schomaker, J. M. Ring expansion of bicyclic methyleneaziridines via concerted, near-barrierless [2,3]-Stevens rearrangement. ACS Catal. 8, 7907-7914 (2018).

64. Davies, H. M. \& Morton, D. Guiding principles for site selective and stereoselective intermolecular $\mathrm{C}-\mathrm{H}$ functionalization by donor/acceptor rhodium carbenes. Chem. Soc. Rev. 40, 1857-1869 (2011).

65. Ahmend, G., Churchhill, M. R. \& Davies, H. L. M. Asymmetric synthesis of highly functionalized 8-oxabicyclo[3.2.1] octene derivatives. J. Am. Chem. Soc. 118, 10774-10782 (1996).

66. Yang, J., Manning, J. R. \& Davies, H. M. L. Direct synthesis of methyl 2-diazo4-aryl-3-butenoates and their application to the enantioselective synthesis of 4-aryl-4-(1-naphthyl)-2-butenoates. Tetrahedron. Asymm. 17, 665-673 (2006).

67. Ju, M., Weatherly, C. D., Guzei, I. A. \& Schomaker, J. M. Chemo- and enantioselective intramolecular silver-catalyzed aziridinations. Angew. Chem. Int. Ed. 56, 9944-9948 (2017).

68. Bhakat, $\mathrm{S}$. The controversial reaction mechanism of Stevens rearrangement: a review. J. Chem. Pharm. Res. 3, 115-121 (2011).

69. Sweeney, J. B. Sigmatropic rearrangements of 'ononium' ylids. Chem. Soc. Rev. 38, 1027-1038 (2009).

70. Adrojewski, T. \& Jonczyk, A. On the [1,4] sigmatropic rearrangement of ammonium benzylides. Tetrahedron Lett. 36, 1355-1358 (1995).

71. Müller, P. \& Rossier, J.-C. Solvent effects on the steric course of the solvolysis of tertiary acyclic derivatives. J. Chem. Soc. Perk. Trans. 2, 2232-2239 (2000).

72. Zhao, C., Toste, F. D., Raymond, K. N. \& Bergman, R. G. Nucleophilic substitution catalyzed by a supramolecular cavity proceeds with retention of absolute stereochemistry. J. Am. Chem. Soc. 136, 14409-14412 (2014).

73. Lebel, H., Lectard, S. \& Parmentier, M. Copper-catalyzed alkene aziridination with $N$-tosyloxycarbamates. Org. Lett. 9, 4797-4800 (2007).

74. Toyooka, N. et al. Synthesis of alkaloid 223A and a structural revision. Org. Lett. 4, 1715-1717 (2002).

75. Okada, T. et al. Synthesis of 8-deoxypumiliotoxin $193 \mathrm{H}$ and 9deoxyhomopumiliotoxin 2070. Tetrahedron Lett. 59, 3797-3800 (2018).

76. Toyooka, N., Fukutome, A., Shinoda, H. \& Nemoto, H. Stereodivergent synthesis of the 2,3,5,6-tetrasubstituted piperidine ring system: An application to the synthesis of alkaloids $223 \mathrm{~A}$ and $205 \mathrm{~B}$ from poison frogs. Tetrahedron 60, 6197-6216 (2004).
77. Chu, L., Ohta, C., Zuo, Z. \& MacMillan, D. W. C. Carboxylic acids as a traceless activation group for conjugate additions: a three-step synthesis of (士)-pregabalin. J. Am. Chem. Soc. 136, 10886-10889 (2014).

\section{Acknowledgements}

J.M.S. thanks the NIH 1R01GM132300-01 and the University of Wisconsin Vilas Faculty Mid-Career Award for support of this work. The NMR facilities at UW-Madison are funded by the National Science Foundation (NSF; CHE-9208463, CHE-9629688) and National Institutes of Health (NIH; RR08389-01). The Q-Exactive mass spectrometer was acquired from an NIH-S10 award (NIH-1S10OD020022-1). I.F. acknowledges financial support from the Spanish MINECO-FEDER (Grants CTQ2016-78205-P and CTQ2016-81797-REDC)

\section{Author contributions}

J.M.S., K.A.N., J.E., and S.C.S designed the research. J.E. and K.A.N. synthesized substrates, developed the reaction conditions, carried out scope studies and post-functionalizations of the dehydropiperidine products. W.T.R. synthesized substrates. I.A.G. carried out the single X-ray crystal structure studies. I.F. carried out the computational studies. J.M.S., S.C.S., J.E. K.A.N., and I.F. co-wrote the paper. All the authors discussed the results and commented on the paper.

\section{Competing interests}

The authors declare no competing interests.

\section{Additional information}

Supplementary information is available for this paper at https://doi.org/10.1038/s41467020-15134-x.

Correspondence and requests for materials should be addressed to J.M.S.

Peer review information Nature Communications thanks Weiming $\mathrm{Wu}$ and the other anonymous, reviewer(s) for their contribution to the peer review of this work.

Reprints and permission information is available at http://www.nature.com/reprints

Publisher's note Springer Nature remains neutral with regard to jurisdictional claims in published maps and institutional affiliations.

(c) (i) Open Access This article is licensed under a Creative Commons Attribution 4.0 International License, which permits use, sharing, adaptation, distribution and reproduction in any medium or format, as long as you give appropriate credit to the original author(s) and the source, provide a link to the Creative Commons license, and indicate if changes were made. The images or other third party material in this article are included in the article's Creative Commons license, unless indicated otherwise in a credit line to the material. If material is not included in the article's Creative Commons license and your intended use is not permitted by statutory regulation or exceeds the permitted use, you will need to obtain permission directly from the copyright holder. To view a copy of this license, visit http://creativecommons.org/ licenses/by/4.0/.

(C) The Author(s) 2020 